RESEARCH ARTICLE

\title{
Impact of inertia constant on frequency dynamics of a power system
}

\section{T.G. Jathunga, A.H. Wijethunga* and J.B. Ekanayake}
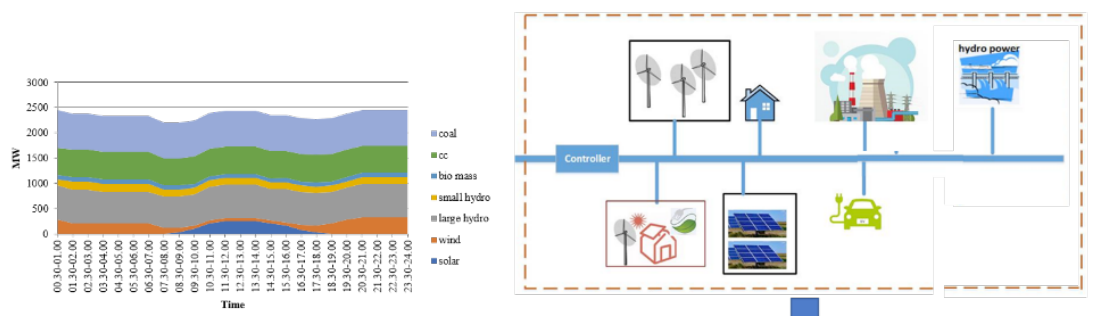

Generation 2020-2030

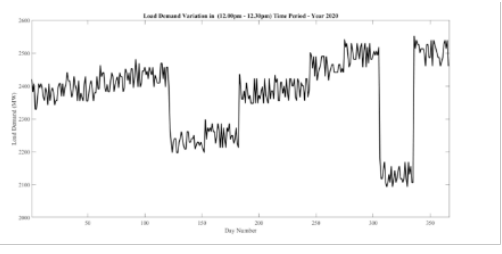

Demand 2020-2030
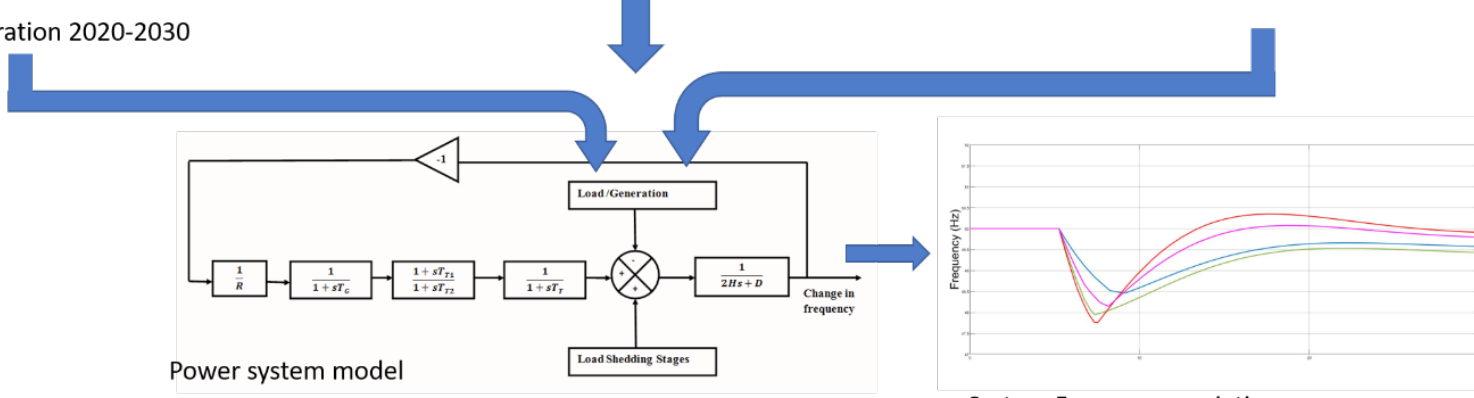

System Frequency variation

\section{Highlights}

- Sri Lankan power system inertia drops by $22 \%$ from 2020 to 2030 due to the high penetration of renewables.

- Sudden disturbance of a $20 \%$ increase of the total demand, the minimum frequency experience in the system drops only by $0.74 \%$.

- Timing of the load shedding should be accurate to bring the system back to normalcy using the primary and secondary frequency response services. 


\title{
RESEARCH ARTICLE
}

\section{Impact of inertia constant on frequency dynamics of a power system}

\author{
T.G. Jathunga ${ }^{1}$, A.H. Wijethunga ${ }^{2, *}$ and J.B. Ekanayake ${ }^{3}$ \\ ${ }^{1}$ Department of Electrical and Electronic Engineering, Sri Lanka Institute of Information Technology, New Kandy Road, \\ Malabe, Sri Lanka. \\ ${ }^{2}$ Department of Materials and Mechanical Technology, Faculty of Technology, University of Sri Jayewardenepura, \\ Homagama, Sri Lanka. \\ ${ }^{3}$ Department of Electrical and Electronic Engineering, Faculty of Engineering, University of Peradeniya, Peradeniya, \\ Sri Lanka.
}

Received: 27/05/2019; Accepted: 10/01/2021

\begin{abstract}
Renewable Energy Sources (RES) are emerging as a mainstream electricity generation option in many parts of the world. However, achieving the frequency stability is a major challenge when the RES penetration is high. This paper investigates the impact of large-scale deployment of Photovoltaics (PVs) on equivalent inertia constant of the power system. In addition, this study examines the minimum frequency and the rate of change of frequency resulting in high penetration of PVs. Case studies are used to demonstrate the frequency dynamics of the projected Sri Lankan power system in 2020 and 2030 considering solar penetration and demand.
\end{abstract}

Keywords: Inertia constant; frequency response; renewable energy; load shedding; rate of change of frequency.

\section{INTRODUCTION}

For a reliable operation of a power system, its operating frequency should be maintained within an acceptable range. In case of a sudden failure in generation or a sudden connection of an additional load, frequency of the system tends to start decreasing and inertia response governs the frequency dynamics of the power system to maintain the frequency within the desired range.

Conventional generating power plants, consisting of large generators and turbines with massive rotating components are electromechanically coupled to the power system and due to the electromechanical coupling they are capable of providing inertia response naturally (Ulbig et al., 2014). In fact, in case of a sudden failure in generation or connection of an additional load, conventional generators reduce their rotational speed and some of the kinetic energy stored in the massive rotating components is released as electrical energy to maintain the nominal system frequency. Unlike conventional generators, renewable generators such as wind generators and PV generators, do not contribute to the system inertia and are incapable of providing additional power to the system in case of any system disturbance (Xypolytou et al., 2018).

The literature discusses the effect of high penetration of renewables for frequency response and ways of mitigating their impact. For example, Ekanayake et al., (2008) assessed the impact of a large penetration of wind turbines on the frequency of the Great Britain (GB) power system. Furthermore, a modification to the wind turbine control systems is suggested to harness inertia response from the wind farms. The participation of Variable Speed Wind Turbines (VSWT) in frequency support is studied and the importance of inertial response is discussed in Krpan et al.'s (2017) research article. Alan et al. (2018) investigated the frequency dynamics using different inertia constants varying between very low to very high.

Impacts of large-scale solar PV generation on North American power system are discussed in the work of Quid et al. (2019). Tan et al. (2018) studied the frequency response of the US Western interconnection under extra high PV penetration. Moreover, practical mitigation solutions are examined by using existing resources to deal with extra high PV penetration levels. In the article of Peng et al. (2014), system frequency excursions that occurs due to the large-scale integration of PV power generation into a smart grid network is analysed and possible solutions are proposed using storage batteries. A fuzzy based control strategy for grid connected solar PV system is proposed by Rajan et al. (2018) which enables participating in frequency control without energy storage.

However, none of the recent research has explicitly discussed the impacts of large-scale solar PV generation on a power system like in Sri Lanka where load shedding is also considered for frequency regulation. Therefore, in this paper as a case study, how PV penetration will affect the frequency stability of the Sri Lankan power system is discussed. A single busbar model of Sri Lankan power system integrates with Under Frequency Load Shedding (UFLS) scheme utilised by Ceylon Electricity Board (CEB) was built in MATLAB Simulink software to examine the frequency stability with respect to the system inertia. 


\section{METHODOLOGY}

\section{PV penetration and Demand Estimation}

In UNDP/ADB publication of 2017 (Singh et al. 2017), daily demand - supply curves in Sri Lanka for years 2020 and 2030 were estimated considering the 100\% RE generation scenario in 2050 and the roadmap of future power generation of Sri Lanka. Those daily demand - supply curves for years 2020 and 2030 were used in identifying the highest PV penetration time period. In reference to those demand-supply curves, highest PV penetration time was identified to be in between 12.00 - 12.30 p.m. period. This study was carried out focusing on load demand values during the highest PV penetration time. The reference on Long Term Generation Expansion Planning of Ceylon Electricity Board, Sri Lanka (Generation Planning UnitCEB, 2020) also highlights the importance of integrating more renewables to the power system with the vision to achieve $50 \%$ of electricity generated from renewable sources (under favourable weather conditions) by 2030.

Two sets of anticipated load demands were used in this study. For the frequency stability analysis of the year 2020, 366 load demand values were taken considering the load demands during the time period $12.00-12.30$ p.m. in each day of the year. Similarly, frequency stability analysis of the year 2030 was also based on 365 load demand values, which are the anticipated load demands during the time period $12.00-12.30$ p.m. in each day of the year 2030 .

\section{Estimating equivalent inertia constant}

\section{Calculating the operating capacity}

The operating capacity of each generator type was calculated considering the installed capacity and the Plant Load Factor (PLF) (Singh et al., 2017). Generator capacities and PLF values for generator types in Sri Lanka were taken as given in the reference (Singh et al., 2017). Operating Capacity of each generator type is calculated using Eq. (1).
Operating Capacity $=$ Generator capacity $\times P L F$

The operating capacities calculated for the Sri Lankan power system is illustrated in Table 1 and Table 2 for years 2020 and 2030 respectively.

\section{Calculation of equivalent inertia constants for each} generator type

The equivalent inertia constant values were assigned for each generator type. For example, all the existing coal power plants in the entire power system were considered as a lumped system and depending on the actual inertia constant values, an equivalent inertia constant value was assumed for coal power plants. In this study, equivalent inertia constants for Large Hydro (LH), Small Hydro (SH), Combined Cycle Diesel power plant (CC), Coal and biomass power plants were assumed to be 3.5, 3.0, 8.0, 4.0 and 3.0 respectively (Wijayaratne, 2017). Solar, and wind power plants were considered as zero inertia power plants.

Calculating the equivalent inertia constant $(H)$ of a power system

Equivalent inertia constant based on the inertia constants of all generators connected to the power system was calculated using equation (2) (Cory et al., 2013). In Table 2 and Table 3, the inertia constants for years 2020 and 2030 for the Sri Lankan power system are illustrated.

$$
H_{\text {system }}=\sum H_{\text {machine }} \times\left(\frac{S_{\text {base, machine }}}{S_{\text {base }, \text { system }}}\right)
$$

where,

$H_{\text {system }} \quad=$ Inertia constant of the entire system

$H_{\text {machine }}^{\text {system }}=$ Inertia constant of each machine

$S_{\text {base, machine }}=$ Base Power of the machine

$S_{\text {base,system }}=$ Base Power of the entire system

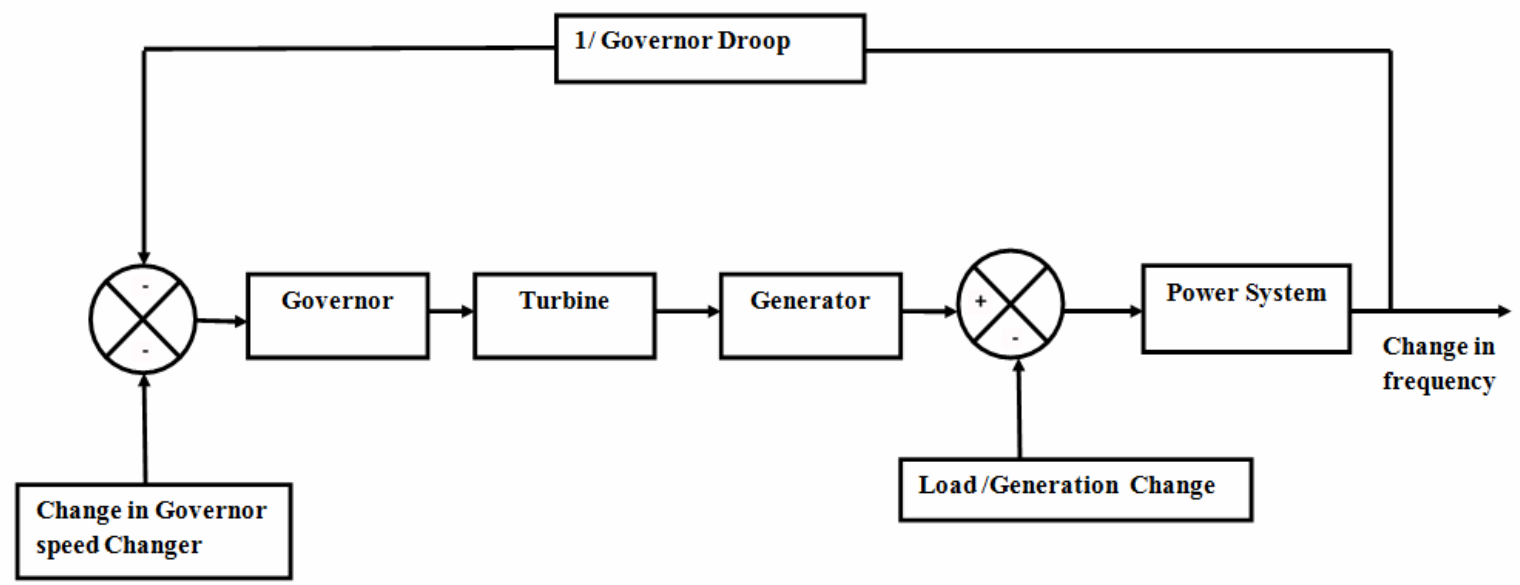

Figure 1: Representation of a turbine generator connected to a power system. 


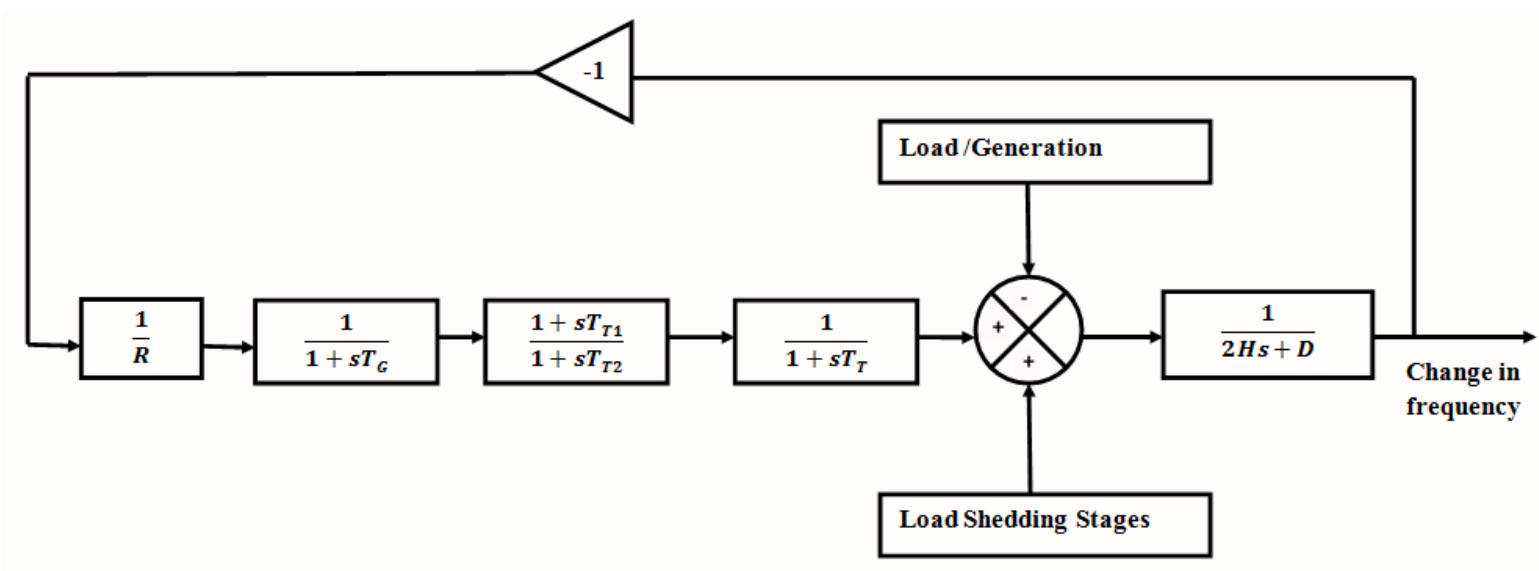

Figure 2 : Single busbar model used for the simulation.

\section{Single busbar model of Sri Lankan power system}

The single busbar model which is used for this study is based on Figure 1 (Cory et al., 2013) and represents an equivalent turbine generator connected to the equivalent power system.

In Sri Lankan power system frequency control is carried out by one of four hydro power stations namely, Victoria, Samanala wewa, New Laxapana and Kothmale. Victoria Hydro Power station is mainly used for frequency control. Therefore, Victoria Hydro Power station was considered as the frequency controlling station throughout this study.

Figure 2 indicates the modified single busbar model of the Sri Lankan power system used for the simulation. In this model, Under Frequency Load Shedding (UFLS) is considered for frequency regulation based on the CEB criteria mentioned in Table 3. (Bambarayanage et al., 2016)

$T_{G}, T_{1}, T_{2}$ and $T_{T}$ are time constants of the Governor, Turbine and Generator of the frequency controlling Hydro power plant, respectively. These time constant values were taken considering the time constants of a typical hydro power plant. $D$ is the damping coefficient and for this study, it was taken as $1 \% . H$ is the inertia constant of the system and of $H$ for each year was calculated.

The equivalent drooping factor, $R$, represents the equivalent droop characteristics and calculation of $\mathrm{R}$ was done using the equation 3 .

$$
\frac{1}{R}=\frac{1}{R f c} \times \frac{\begin{array}{c}
\text { Rated Capacity of the } \\
\text { frequency controlling maching }
\end{array}}{\text { Base Power of the System }}
$$

where,

$R f_{c}=$ Drooping factor of the frequency controlling machine

\section{Load Shedding Operation}

For instance, when the power system's self-regulation fails to maintain the stability of the power system, the system frequency tends to keep dropping until the generation balances with the load demand. Load shedding operation removes loads from the power system when a load generation imbalance occurs. Basic objective of a load shedding operation is to avoid the power system from collapsing.

\section{RESULTS AND DISCUSSION}

\section{PV penetration}

Based on the data acquired from reference (Singh et al., (2017), in Sri Lanka, daily generation planning curve for the year 2020 was obtained and is shown in Figure 3. According to the generation planning curve, the highest solar penetration for the year 2020 occurs during 12.00 12.30 p.m. time period.

Figure 4 indicates the daily generation planning curve for the year 2030 and it also reveals 12.00 - 12.30 p.m. time period as the highest solar penetration period.

\section{Load Demand Variation}

Generation planning curves suggest that highest solar penetration for both 2020 and 2030 years occurs during the time period of $12.00-12.30$ p.m. Therefore, anticipated load demands for the $12.00-12.30$ p.m. time slot were considered and shown in Figures 5 and 6 for 2020 and 2030 respectively. 


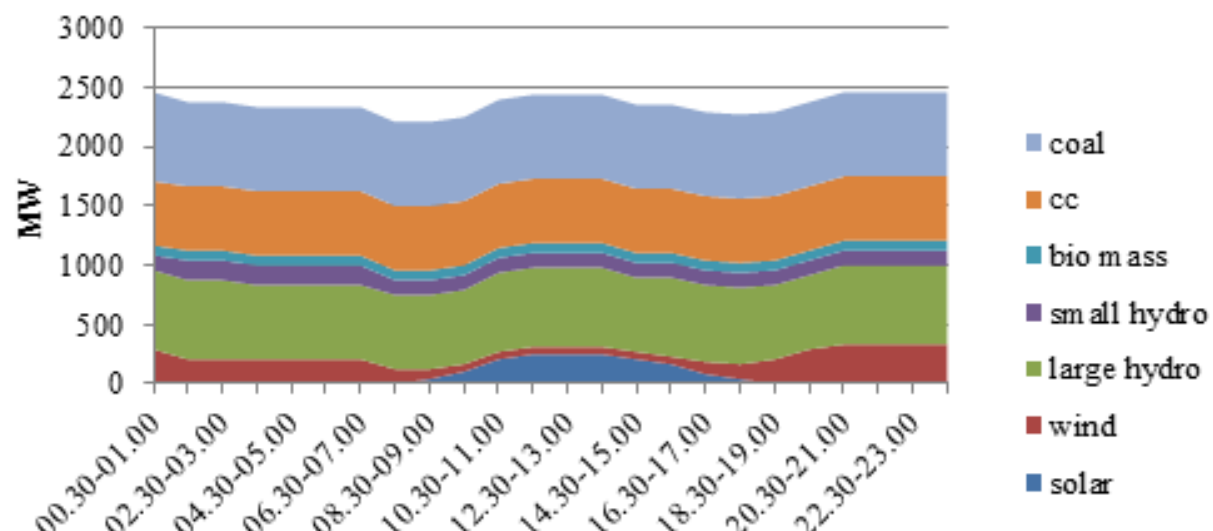

Figure 3: Daily Generation Planning Curve for year 2020.

Time

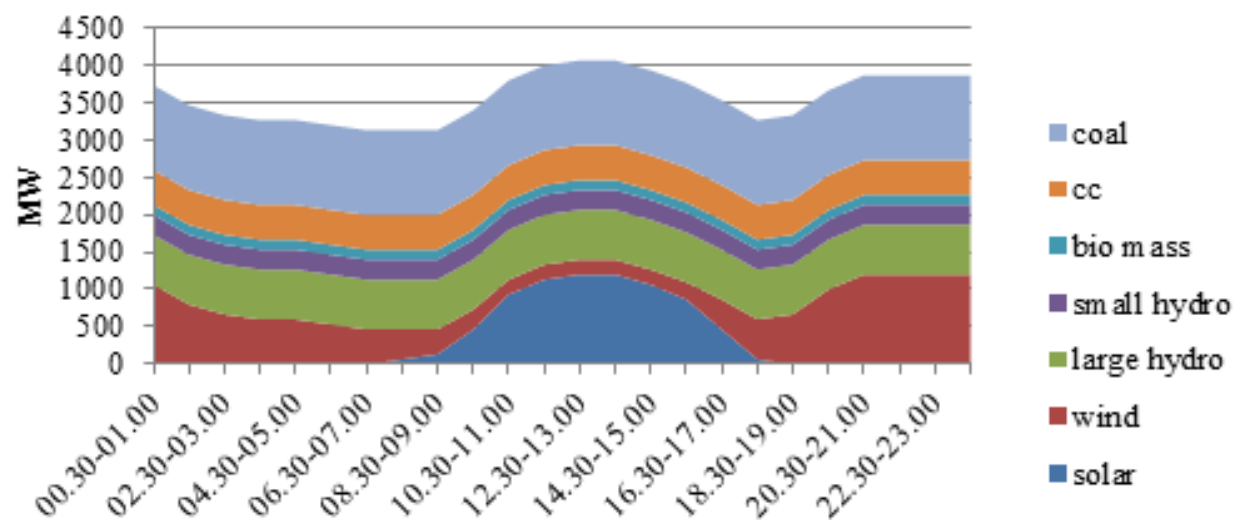

Time

Figure 4 : Daily Generation Planning Curve for year 2030.

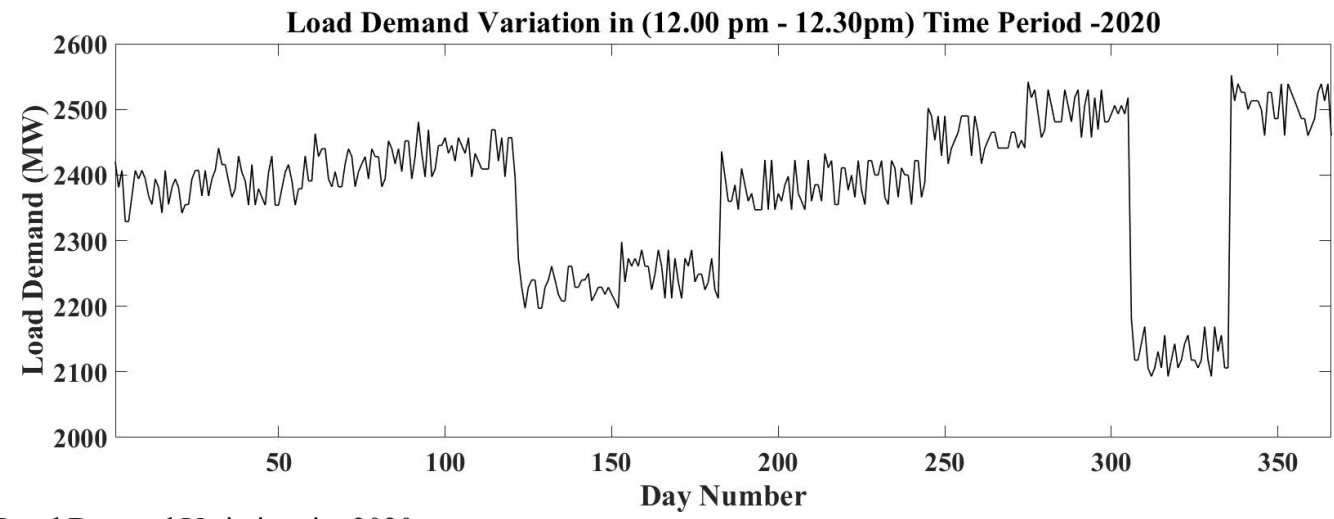

Figure 5 : Load Demand Variation in 2020.

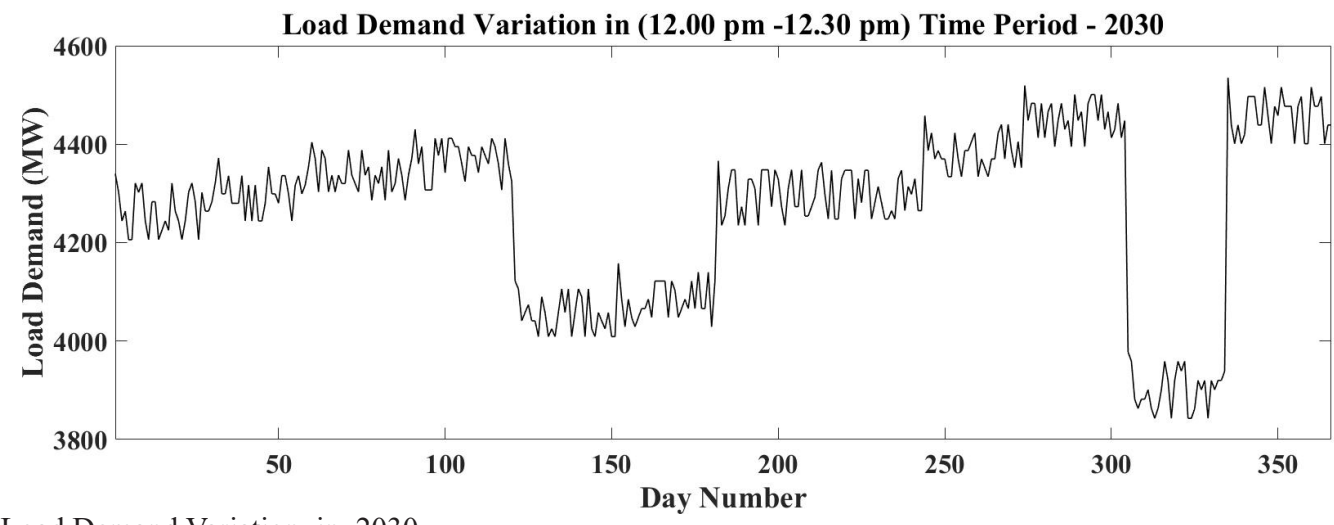

Figure 6 : Load Demand Variation in 2030. 


\section{Calculation of equivalent inertia constants}

Equivalent inertia constant for the year 2020

Sri Lanka's total installed generator capacity is estimated to be $4888 \mathrm{MW}$ in 2020 (Singh et al., 2017). As the study was carried out in off-peak time duration when the solar generation is the maximum, the generation sources in operation of the Sri Lankan power system is assumed as in Table 1. It is worth noting that during the off-peak hours there are no single-cycle oil generation in operation. Depending on the plant load factors incorporated with each generator type, the operating capacity is calculated as 1927.91 MW.

The equivalent inertia constant $\left(\mathrm{H}_{\mathrm{eq}}\right)$ for the entire power system was calculated based on the inertia constants that were assumed to be compatible with a particular generator type. These calculations are summarized in Table 1.

\section{Equivalent inertia constant for the year 2030}

The generation capacity in 2030 is estimated as $8836 \mathrm{MW}$ (Singh et al., 2017). When considering the plant load factors, the total operating capacity is calculated as 3151.08 MW. Using the assumed inertia constants for particular generator types and the estimated generation statistics, the equivalent inertia constant $\left(\mathrm{H}_{\mathrm{eq}}\right)$ was calculated for the year 2030. The summary of the calculations is given in Table 2.

\section{Calculation of system parameters}

Equivalent Drooping Factor

For the single busbar model shown in Figure 1, the value of drooping factor $(1 / \mathrm{R})$ is calculated based on Eq.(3). The drooping factor of Victoria Hydro Power Station was taken as 1.2\% (Wijayaratne, 2017). Table 3 summarizes the calculated equivalent drooping factor for each year.

\section{Under Frequency Load Shedding (UFLS) Schemes}

Considering the Sri Lankan power system, under frequency load shedding criteria used for the simulation model is given in Table 4 (Bambarayanage et al., 2016)

\section{Simulation results}

In order to investigate the impact of inertia constant on frequency response, a sudden disturbance with a $20 \%$ of the total demand at the selected time was applied to the system. Pre-determined load demand in the highest solar penetration time period, i.e. from 12.00 to 12.30 p.m., was considered for both years (Singh et al., 2017). Simulation was done considering 365 loads in peak PV period for each year.

The analysis of the impact of inertia constant during a sudden disturbance was carried out by considering two parameters: minimum frequency and the Rate of Change

Table 1: Equivalent inertia constants for the year 2020

\begin{tabular}{lccccc}
\hline \multicolumn{1}{c}{ Generator type } & $\begin{array}{c}\text { Installed Capacity } \\
\text { (MW) }\end{array}$ & $\begin{array}{c}\text { Plant Load } \\
\text { Factor (\%) }\end{array}$ & $\begin{array}{c}\text { Operating } \\
\text { Capacity (MW) }\end{array}$ & $\mathbf{H}_{\text {eq }}$ \\
\hline Large Hydro & 1536 & 40 & 614.40 & 3.5 & 1.115 \\
\hline Small Hydro & 413 & 39 & 161.07 & 3.0 & 0.251 \\
\hline Combined Cycle diesel power & 594 & 50 & 297.00 & 8.0 & 1.232 \\
\hline Coal & 825 & 60 & 495.00 & 4.0 & 1.027 \\
\hline Biomass & 124 & 70 & 86.80 & 3.0 & 0.135 \\
\hline Wind & 690 & 30 & 207.00 & 0 & 0 \\
\hline Solar & 392 & 17 & 66.64 & 0 & 0 \\
\hline Total & 4574 & & 1927.91 & & 3.76 \\
\hline
\end{tabular}

Table 2: Equivalent inertia constants for the year 2030

\begin{tabular}{lccccc}
\hline Generator type & $\begin{array}{c}\text { Installed } \\
\text { Capacity (MW) }\end{array}$ & $\begin{array}{c}\text { Plant Load } \\
\text { Factor (\%) }\end{array}$ & $\begin{array}{c}\text { Operating } \\
\text { Capacity (MW) }\end{array}$ & $\mathbf{H}_{\text {eq }}$ \\
\hline Large Hydro & 1576 & 40 & 630.40 & 3.5 & 0.700 \\
\hline Small Hydro & 653 & 39 & 254.67 & 3.0 & 0.242 \\
\hline Combine Cycle & 594 & 50 & 297.00 & 8.0 & 0.754 \\
\hline Coal & 1425 & 60 & 855.00 & 4.0 & 1.086 \\
\hline Biomass & 194 & 70 & 135.80 & 3.0 & 0.129 \\
\hline Wind & 2313 & 30 & 393.21 & 0 & 0 \\
\hline Solar & 1950 & 17 & 585.00 & 0 & 0 \\
\hline Total & 8705 & & 3151.08 & & 2.911 \\
\hline
\end{tabular}


Table 3: Calculation of equivalent drooping factors

\begin{tabular}{ccccc}
\hline Year & $\begin{array}{c}\text { Drooping factor } \\
\text { of the frequency } \\
\text { controlling centre } \\
\mathbf{( \% )}\end{array}$ & $\begin{array}{c}\text { Rated Capacity of the } \\
\text { frequency controlling } \\
\text { machine (MW) }\end{array}$ & System Base & $\begin{array}{c}\text { Equivalent Drooping } \\
\text { Factor }\end{array}$ \\
\hline 2020 & 1.2 & 70 & 1927.91 & 3.03 \\
\hline 2030 & 1.2 & 70 & 3151.08 & 1.85 \\
\hline
\end{tabular}

$T_{G}, T_{T 1}, T_{T 2}, T_{T}$ time constants of a typical hydro power plant are $0.2,2,12$ and 0.3 respectively (Wijayaratne, 2017).

Table 4: Load Shedding Scheme used for the simulation model

\begin{tabular}{ll}
\hline Frequency State & Magnitude and time delay of load shedding \\
\hline $\mathrm{f} 48.75 \mathrm{~Hz}$ & No load shed \\
\hline $\mathrm{f}<48.75 \mathrm{~Hz}$ & $6.5 \%$ of load $100 \mathrm{~ms}$ time delay \\
\hline $\mathrm{f}<48.5 \mathrm{~Hz}$ & $6.5 \%$ of load $500 \mathrm{~ms}$ time delay \\
\hline $\mathrm{f}<48.25 \mathrm{~Hz}$ & $12 \%$ of load $500 \mathrm{~ms}$ time delay \\
\hline $\mathrm{f}<48 \mathrm{~Hz}$ & $9 \%+3.5 \% *=12.5 \%$ of load $500 \mathrm{~ms}$ time delay \\
\hline $\mathrm{f}<47.5 \mathrm{~Hz}$ & $3 \%+4.5 \% *=7.5 \%$ of load Instantaneous \\
\hline $\mathrm{f}<49.0 \mathrm{~Hz} \&-0.85<\mathrm{df} / \mathrm{dt}$ & $13 \%+3 \% *+4.5 \% *=21 \%$ of load $100 \mathrm{~ms}$ time delay \\
\hline
\end{tabular}

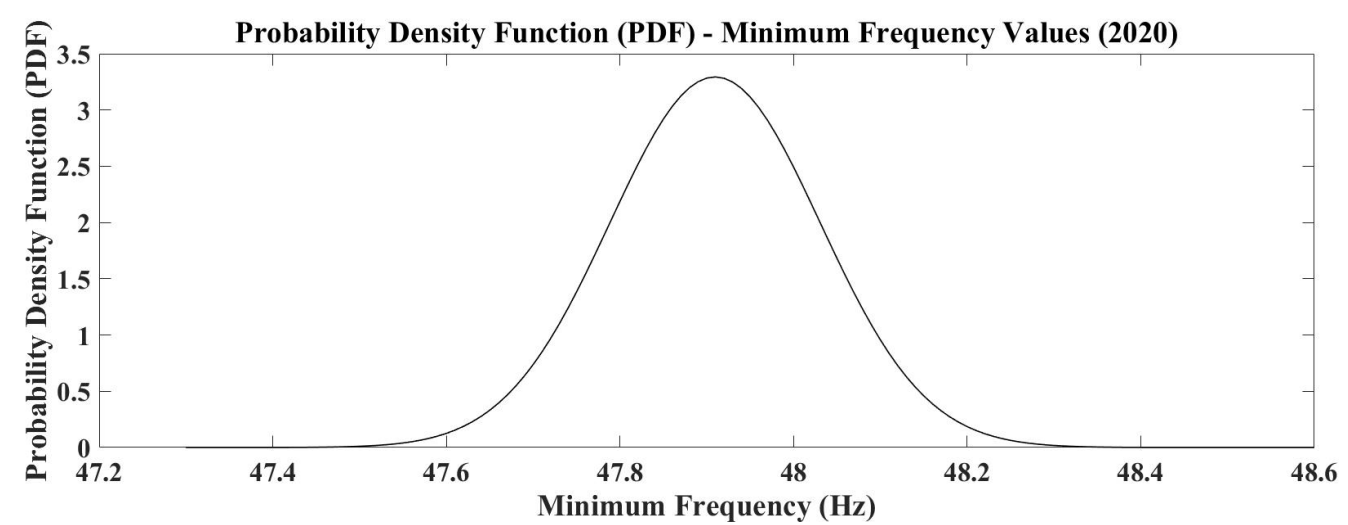

Figure 7: PDF curve of minimum frequency for year 2020.

of Frequency (ROCOF). Hence, the system's minimum frequency during each disturbance was recorded for each year. Furthermore, the time taken to drop the frequency from its nominal frequency value to minimum frequency value was recorded. Thereafter, the Probability Density Function (PDF) was plotted for the minimum frequency values and the Rate of Change of Frequency (ROCOF) values in each year.

\section{Frequency response for the year 2020}

Probability Density Function (PDF) curves of the minimum frequency and ROCOF for the year 2020 were plotted separately and they are shown in Figures 7 and 8 respectively.

\section{Frequency response for the year 2030}

Figures 9 and Figure 10 show the PDF curves of minimum frequency and ROCOF for the year 2030 respectively.

Table 5 summarises results obtained for each year. As per the table, the mean value of the minimum frequency in 2020 is $47.910 \mathrm{~Hz}$ with a system inertia of 3.76. In 2030, the equivalent inertia of the system reduces to 2.91 and the mean value of the minimum frequency becomes 47.556 Hz. Furthermore, the mean value of frequency dropping rate in 2020 is $1.007 \mathrm{~Hz} / \mathrm{s}$. In 2030 with a reduced inertia, the mean value of the frequency dropping rate increases to $1.440 \mathrm{~Hz} / \mathrm{s}$. 


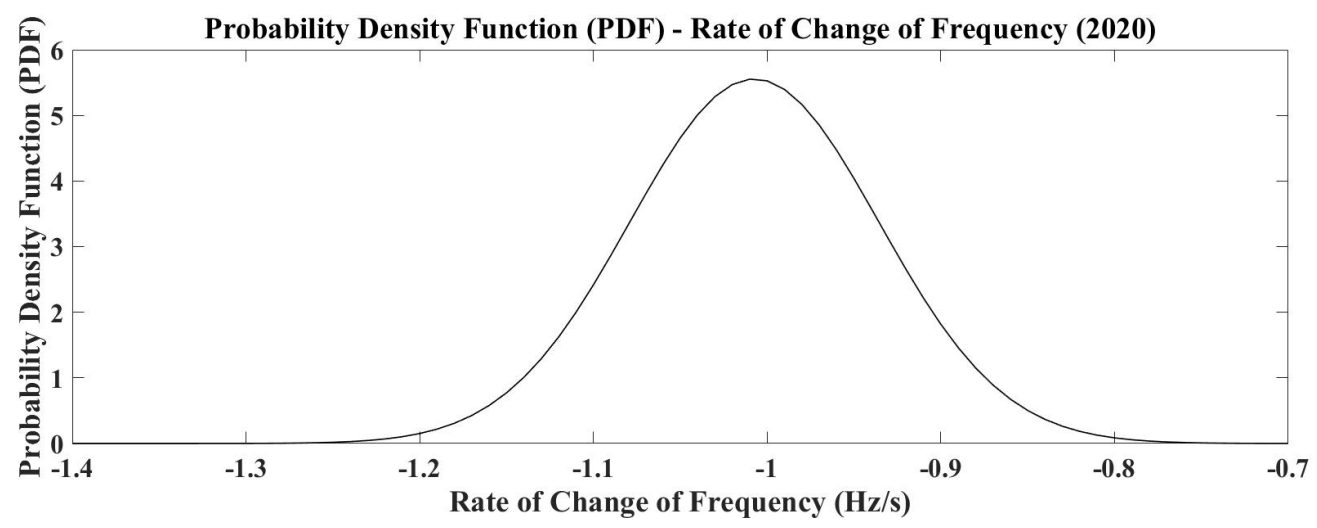

Figure 8: PDF curve of ROCOF for year 2020.

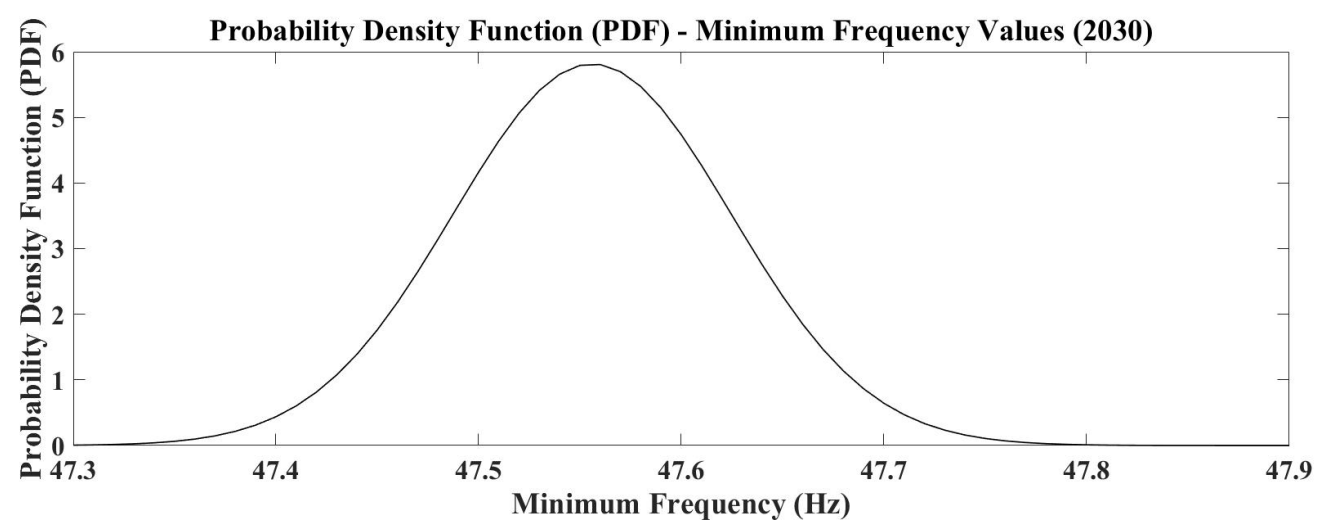

Figure 9: PDF curve of minimum frequency for year 2030.

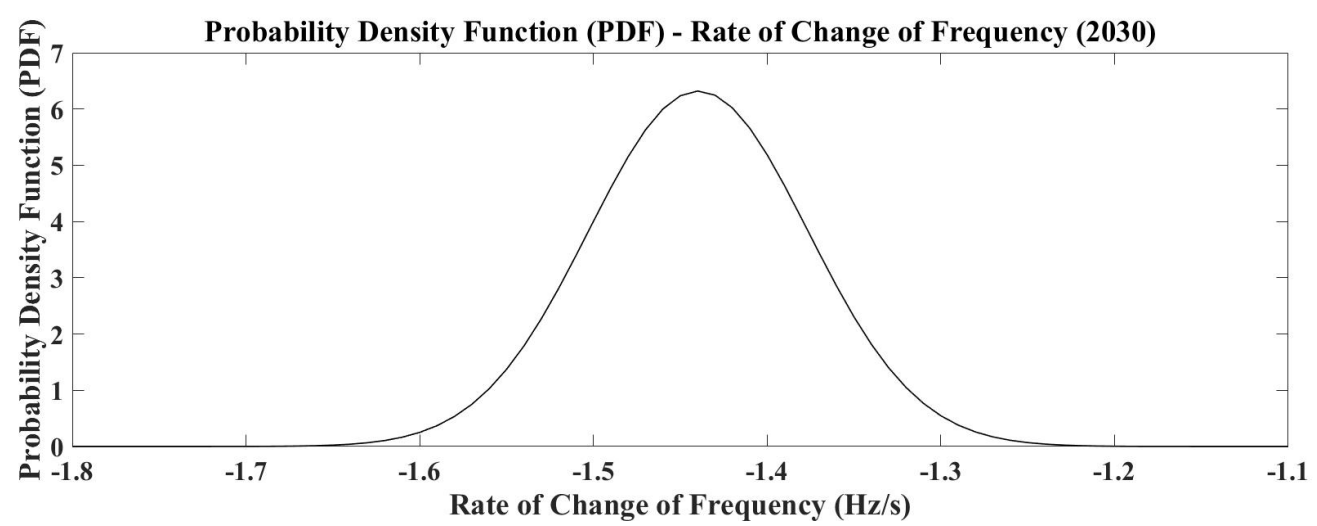

Figure 10: PDF curve of ROCOF for year 2030.

Table 5: Summary of the results

\begin{tabular}{cll}
\hline Result & Year 2020 & Year 2030 \\
\hline Equivalent Inertia Constant & 3.76 & 2.91 \\
\hline Mean value of minimum frequency $(\mathrm{Hz})$ & 47.910 & 47.556 \\
\hline Variance of minimum frequency & 0.015 & 0.005 \\
\hline Mean value of ROCOF $(\mathrm{Hz} / \mathrm{s})$ & -1.007 & -1.440 \\
\hline Variance of ROCOF & 0.005 & 0.004 \\
\hline
\end{tabular}

\section{CONCLUSION AND FUTURE WORK}

This study investigated the impact of large-scale deployment of Photovoltaic on the equivalent inertia constant of the power system. Even though the system inertia drops by $22 \%$ from 2020 to 2030 due to the high penetration of renewables, with a sudden disturbance of a $20 \%$ increase of the total demand, the minimum frequency experience in the system drops only by $0.74 \%$. However, ROCOF will increase by nearly $50 \%$ and therefore, the timing of the load shedding should be accurate to bring the system back to normalcy using the primary and secondary frequency response services. In conclusion, the results of the study 
imply that the frequency performance of the power system deteriorates with the increased penetration of PV but due to the reverse effect caused by the UFLS scheme, it is not alarming.

As future studies, the impact of the high penetration of solar PV to the Sri Lankan power system can be analysed using a number of scenarios. As demand side integration (DSI) will become mainstream option with high penetration of renewables, DSI could be added to the single busbar model considering the communication latency and people's behaviour.

\section{ACKNOWLEDGEMENT}

The authors would like to acknowledge support provided by the Department of Electrical and Electronics Engineering, University of Peradeniya.

\section{DECLARATION OF CONFLICT OF INTEREST}

The authors declare no conflict of interest.

\section{DATA AVAILABILITY}

All relevant data are available on request from corresponding author.

\section{REFERENCES}

Alan Audu, N. (2018). Effect of Inertia Constant on Generator Frequency and Rotor Angle. Engineering and Applied Sciences 3(1): 6, DOI: 10.11648/j. eas.20180301.12.

Bambaravanage, T., Kumarawadu, S. and Rodrigo, A. (2016). Comparison of three Under-Frequency Load Shedding Schemes referring to the Power System of Sri Lanka. Engineer: Journal of The Institution of Engineers, Sri Lanka 49(1): 41-52, DOI: 10.4038/ engineer.v49i1.6917.

Cory, B., Jenkins, N., Ekanayake, J., Strbac, G. and Weedy, B. (2013). Electric Power Systems (p. chapter 5). Hoboken, N. J.: Wiley.

Ekanayake, J., Jenkins, N. and Strbac, G. (2008). Frequency Response from Wind Turbines. Wind Engineering 32(6): 573-586.

Generation Planning Unit, CEB (2020), Long Term Generation Expansion Planning Studies 2020- 2039, Transmission and Generation Planning Branch, Ceylon Electricity Board, Sri Lanka, Available From: https:// ceb.lk/.

Krpan, M. and Kuzle, I. (2017). Inertial and primary frequency response model of variable-speed wind turbines. The Journal of Engineering 2017(13): 844848, DOI: 10.1049/joe.2017.0449.

Peng, X., So, P. and Tan, K. (2014). An analysis on system frequency of a smart grid network with large scale PV power generation.2014 IEEE PES Asia-Pacific Power and Energy Engineering Conference (APPEEC), DOI 10.1109/APPEEC.2014.7066128.

Qaid, K., Gan, C., Salim, N. and Shamshiri, M. Impacts of Large Scale solar photovoltaic generation on power system frequency response.5th IET International Conference on Clean Energy and Technology
(CEAT2018), DOI: 10.1049/cp.2018.1309.

Rajan, R. and Fernandez, F. (2018). Fuzzy based control of Grid connected photovoltaic system for enhancing system inertial response. $201853^{\text {rd }}$ International Universities Power Engineering Conference (UPEC),DOI: 10.1109/UPEC.2018.8542008.

Singh ,M., Keswani, S., Chitkara, P., Joseph, R., Singha, H., Sen, S., Mahindru, G., Rao, V., Sumanasekaran, P. and Shazaad, N. (2017). 100\% Electricity Generation Through Renewable Energy 2050- Assessment of Sri Lanka's Power Sector, Asian Development Bank \& United Nations Development Programme, Available From: http://www.adb.org, http://www.undp.org (2019/10/25).

Tan, J., Zhang, Y., You, S., Liu, Y. and Liu, Y. (2018). Frequency Response study of U.S. Western Interconnection under extra high photovoltaic generation.2018 IEEE Power \& Energy Society General Meeting (PESGM), DOI: 10.1109/ PESGM.2018.8586163.

Ulbig, A., Borsche, T. and Andersson, G. (2014). Impact of Low Rotational Inertia on Power System Stability and Operation. IFAC Proceedings Volumes 47(3): 72907297, DOI: 10.3182/20140824-6-ZA-1003.02615.

Wijayaratne, R.R.L.L. (2017). Investigating the possibility of using a smart transformer for a dynamic volt var control, M.Phil. thesis, University of Peradeniya.

Xypolytou, E., Gawlik, W., Zseby, T. and Fabini, J. (2018). Impact of Asynchronous Renewable Generation Infeed on Grid Frequency: Analysis Based on Synchrophasor Measurements. Sustainability 10(5): 1605-1614, DOI:10.3390/su10051605. 